\title{
Anterior Trimming vs Outer Displacement of Inferior Turbinate: A Comparative Study at a Tertiary Care Hospital
}

\author{
Habib-Ur-Rehman, Fazal-I-Wahid, Bakht Zada, Muhammad Javaid, Naseemul Haq
}

\section{ABSTRACT}

Background: Obstruction of nose due to enlargement of inferior turbinate is a very common problem faced by ENT surgeon. In this study a useful technique for treatment of inferior turbinate hypertrophy is described.

Objective: To determine the surgical outcome and complications of the two surgical procedures.

Material and Methods: This non-randomized comparative study was performed in the Department of ENT, HNS, MTI/LRH, Peshawar, Pakistan, from June 01, 2017 to May 31, 2018. After ethical approval, sample size of 112 was calculated and patients included of both genders fulfilling inclusion criteria. After taking consent patients were equally divided into two groups with nonrandom number table method. Both subjective and objective assessment was carried out and observations were recorded on a predesigned proforma. Data were analyzed using SPSS 20.

Results: Total patients were 112 , in age range from 16 to 50 years. There were $56(50 \%)$ patients in each group. Males were 71 and female 41 with male to female ratio of $1.7: 1$ and mean age was $32.92 \pm$ S.D 10.29 years. Relief from nasal obstruction obtained was $94.64 \%$ and $92.86 \%$ in Group A and B respectively. Headache was relived $83.34 \%$ and $88.38 \%$ in Group A and B respectively. The complications experienced were post operative bleeding, adhesion formation and crusting $2.6 \%, 3.5 \%$ and $1.78 \%$ respectively. Statistics showed no significant difference between the two operations $(p>0.05)$.

Conclusion: Both trimming and outer displacement of hypertrophied inferior turbinate are effective procedures for relief of nasal obstruction but there was no significant difference between the two techniques in term of outcome and complications.

Key Words: Inferior turbinate, Hypertrophy, Trimming, Outer displacement, Nasal obstruction

This article may be cited as: Rehman HU, Wahid F, Zada B, Javaid M, Haq N. Anterior trimming vs outer displacement of inferior turbinate: A comparative study at a tertiary care hospital. J Saidu Med Coll Swat 2021;11(4):170-5.doi.org/10.52206/jsmc.2021.11.3.654

\section{INTRODUCTION}

Nose is very important organ of human being, performing two essential functions of breathing and smell. Beside its anatomical cosmetic role in one's personality expression its physiological importance cannot be undermined. Comfortable nasal breathing is essential for life. ${ }^{1}$ Any difficulty in nasal breathing may be search out and treated accordingly. Pathological conditions of nose leading to difficulty in breathing include deviated nasal septum, inferior turbinate hypertrophy, benign and malignant nasal masses occurring separately or in combination. ${ }^{2,}{ }^{3}$ After DNS (deviated nasal septum) inferior turbinate hypertrophy is the more common clinical condition needs treatment to relive nasal obstruction. ${ }^{4}$ In the existing literature various surgical techniques have been reported for reduction of size of inferior turbinate hypertrophy including turbinectomy, turbinoplasty, cauterization, radiofrequency, laser and outer displacement. But until now no one procedure has been established as gold standard. ${ }^{5}$ There are so many complications of

Department of Ear, Nose and Throat (ENT), Head \& Neck Surgery, Medical Teaching Institute (MTI), Lady Reading Hospital (LRH), Peshawar Pakistan.

Correspondence: Dr. Fazal-i-Wahid

Assistant Professor E.N.T

E-mail:drfazal58@gmail.com

Cell: +923439083224 intervention for reduction of size of inferior Turbinate hypertrophy including bleeding, crusting, empty nose syndrome, synachae, atrophic rhinitis and dryness. In the past every procedure has been tried by various otorhinolaryngologists to study the outcome and associated complications. ${ }^{3,4}$ Khan and collegues also conducted a study on effectiveness of total turbinectomy in Departments of Otolaryngology Combined Military Hospital Kharian and Peshawar, but the procedure of total turbinectomy on one hand gives relief from nasal obstruction may cause a very annoying condition for the patient due to crusting and loss of sensory mucosa of inferior turbinate, so the technique of total inferior turbinectomy is no longer favored by surgeons. ${ }^{6}$ Similarly Imad and colleagues also carried study on submucosal diathermy versus partial inferior turbinectomy for nasal obstruction in local set up and concluded that there was no difference between the two techniques, but the inherited demerits of recurrence in case of submucosal diathermy and bleeding and crusting associated with partial turbinectomy cannot be avoided. ${ }^{7}$ In other study radiofrequency with outer displacement of inferior turbinate is compared with radiofrequency alone and concluded that radiofrequency in combination with outer displacement of inferior turbinate gave better results. However the facility of radiofrequency is not available in our set up and the combination of two procedures itself is very cumbersome. ${ }^{5}$ 
Trimming of the anterior end of inferior turbinate is a less destructive procedure, and in current literature no study on its efficacy has been conducted to best of my knowledge. Similarly outer displacement is also a more tissue preserving procedure which on one hand maintains the sensory mucosa of inferior turbinate and on the other hand provides sufficient area for passage of air through nose. Nasal bleeding after turbinectomy sometime becomes very lethal and needs transfusion to the patients and even reexploration of the bleeding point. Likewise in turbinectomy there is loss of sensory mucosa of the inferior turbinate which may results in a condition called empty nose syndrome, where nose is wide open but patient feels obstruction due to loss of sensory mucosa of inferior turbinate. ${ }^{8}$ Crusting and bleeding are so annoying for the patients that, they may attempt suicide. In nutshell there are numerous surgical techniques described in literature in different times but due to poor success rate or associated complications, no single procedure got worldwide popularity.

As we are living in a resource limited country no sophisticated technology like laser, radiofrequency or other advance technological facility available in our institution for treatment of this common ENT problem. Keeping in view the importance of nasal obstruction due to hypertrophy of inferior turbinate and no study was carried out on these two minimal destructive procedures in our local setting. So this study was aimed to compare surgical outcome and associated complications of anterior trimming vs outer displacement of hypertrophied inferior turbinate.

\section{MATERIALS AND METHODS}

This non-randomized comparative study was performed in the Department of Ear, Nose and Throat (ENT), Head and Neck Surgery, Medical Teaching Institute (MTI), Lady Reading Hospital (LRH), Peshawar, Pakistan, from June 01, 2017 to May 31, 2018. Sample size was calculated using online sample size calculator named Sample size calculator - Cleveland Clinic Risk Calculator Library software and sample size was 112 keeping 0.05 level of significance and 0.8 power $(1-ß)$ of test. ${ }^{9}$ This study was approved from institutional ethical board. Patients of both genders in the age range of 16 to 50 years qualifying inclusion criteria were included Patients complaining of nasal blockage with inferior turbinate enlargement with or without deviated nasal septum (DNS) not responding to medical therapy were included, while those with nasal mass, nasal bleeding, acute rhinosinusitis or previous nasal surgery having inferior turbinate hypertrophy were excluded. Data were collected exercising convenience non-probability sampling technique. Well informed written consent was obtained from all patients and they were distributed into two groups using non-random number table. Group A constituted patients subjected to trimming while Group B consisted of the patients subjected to outer displacement of hypertrophied inferior turbinates. All the patients were properly assessed in terms of detailed history of rhinological pathology and meticulous examination focusing on nasal evaluation. The investigations carried out were baseline investigation and X-Ray and CT scan Nose and para nasal sinuses where needed. All the patients were evaluated by the author (Assistant Professor E.N.T for 06 years (DLO, FCPS) both subjectively and objectively for nasal obstruction before and after surgery. Objective assessment of nasal patency was performed by using calibrated metallic ruler hold infront of nares in horizontal plane just above the upper lip. Each nostril was checked separately and the total area of misting on the ruler was calculated. This test was performed before and after operation. Patient's subjective feeling of nasal patency narrated by patients and subjective patency checked with calibrate metallic ruler pre and postoperatively were also noted. Surgical intervention was performed after complete preoperative work up.

\section{Procedure}

After admission into ENT department patients were evaluated by anesthetist for general anesthesia. In Operation Theater in aseptic environment nasal cavities were packed with ribbon gauze imbued in $4 \%$ xylocaine with adrenaline. The patients were subjected to general anesthesia with intubation in supine position. After aseptic draping $2 \%$ xylocaine having 1 in 100000 adrenaline was infiltrated in nasal mucosa of nasal septum and inferior turbinate areas on both sides of nose in both groups. Septoplasty was performed and in group A anterior $1 / 5^{\text {th }}$ of inferior turbinate was first crushed with straight artery forcep and the cut with turbinectomy scissor, while in group B inferior turbinate was first infractured superiomedially with freer elevator and then displaced laterally. Then hemostasis was secured and nasal cavity was suctioned properly and each nostril was splinted 
and packed with ribbon gauze impregnated with polyfax ointment for 24 hours. Patients were put on antibiotics, analgesics and antihistaminic. Patients were discharged on next day after removal of nasal packs and were instructed to come for follow up on $10^{\text {th }}$ postop day and on 3rd month. On each follow up visit both subjective and objective assessment were carried out as mentioned above. All observations were recorded on a predesigned proforma. Data were analyzed using SPSS 20. Mean \pm standard deviation (SD), and frequencies and percentages were calculated for quantitative and qualitative data respectively.
Chi-square test was used keeping confidence interval $(\mathrm{Cl})$ at $95 \%$ and $\mathrm{P}<0.05$ was considered significant.

\section{RESULTS}

In this study total patients were 112, ranged in age from 16 to 50 years. There were 56(50\%) patients in each group. Males were 71 and female 41 with male to female ratio of $1.7: 1$ and mean age was $32.92 \pm$ S.D 10.29 years. Majority of patients were in $3^{\text {rd }}$ decade $43(38.4 \%)$ followed by $4^{\text {th }}$ decade 30 $(26.8 \%)$ of life. Table 1.

Table 1: Demographic Data of patients (n-112).

\begin{tabular}{|l|c|c|c|c|}
\hline & \multicolumn{2}{|c|}{ Group A } & \multicolumn{2}{c|}{ Group B } \\
\hline & Frequency & Percentage & Frequency & Percentage \\
\hline Male & 42 & 37.5 & 29 & 25.8 \\
\hline Female & 23 & 29.5 & 18 & 16.0 \\
\hline Age & & & & \\
\hline$<\mathbf{2 0}$ & 8 & 7.1 & 6 & 5.4 \\
\hline $\mathbf{2 1 - 3 0}$ & 20 & 17.8 & 23 & 20.5 \\
\hline $\mathbf{3 1 - 4 0}$ & 18 & 16.1 & 12 & 10.7 \\
\hline$>\mathbf{4 1}$ & 16 & 14.2 & 9 & 8.0 \\
\hline
\end{tabular}

On subjective assessment of patients preoperative nasal obstruction was found in all 112 $(100 \%)$ patients. Three months after surgery nasal obstruction remained in $3(2.6 \%)$ patients in Group A, while in Group B nasal obstruction persisted in 4(3.5\%). Relief from nasal obstruction was $94.64 \%$ and $92.86 \%$ in Group A and B respectively. The improvement in nasal discharge was $81.49 \%$ and $63.16 \%$ in group $A$ and $B$ and headache was relived $83.34 \%$ and $88.38 \%$ in Group Aand B respectively.

Table 2: Finding of Subjective Assessment of both groups pre and postoperatively.

\begin{tabular}{|l|c|c|c|c|c|c|c|c|c|c|}
\hline & \multicolumn{4}{|c|}{ Group A } & \multicolumn{5}{c|}{ Group B } \\
\hline \multirow{2}{*}{ Presentation } & \multicolumn{2}{|c|}{ Preop } & \multicolumn{2}{|c|}{ Postop } & & \multicolumn{2}{c|}{ Preop } & \multicolumn{2}{c|}{ Postop } & \\
\cline { 2 - 13 } & Frequency & $\%$ age & Frequency & $\%$ age & Relief\% & Frequency & $\%$ age & Frequency & \%age & Relief\% \\
\hline Nasal Obstruction & 56 & 50 & 3 & 2.6 & 94.64 & 56 & 50 & 4 & 3.5 & 92.86 \\
\hline Nasal Discharge & 27 & 24.10 & 5 & 4.46 & 81.49 & 19 & 16.96 & 7 & 6.25 & 63.16 \\
\hline Headache & 36 & 32.14 & 6 & 16.66 & 83.34 & 43 & 38.39 & 5 & 4.46 & 88.38 \\
\hline Snoring & 17 & 15.17 & 7 & 6.25 & 58.83 & 22 & 19.64 & 9 & 8.03 & 59.1 \\
\hline
\end{tabular}

Regarding objective assessment all patients were grouped into four categories on basis of air passage through nasal cavities measured with calibrated metallic ruler. In category 1 Patients had severe nasal obstruction (misting area on calibrated metallic ruler was $\leq 1.9 \mathrm{~cm}$ of the total area infront of the nostril), category 2 moderate nasal obstruction (misting area on calibrated 
metallic ruler was $22.9 \mathrm{~cm}$ of the total area infront of the nostril), category 3 mild nasal obstruction (misting area on calibrated metallic ruler was 3 $3.9 \mathrm{~cm}$ of the total area infront of the nostril) and category 4 with slight nasal obstruction (misting area on calibrated metallic ruler was $\geq 4 \mathrm{~cm}$ of the total area infront of the nostril). In group A (anterior trimming of hypertrophied inferior turbinate) there were $25(22.32 \%)$ patients in category 2 and $19(16.96 \%)$ patients in category 3 preoperatively which were reduced to $14(12.5 \%)$ and $18(16.07 \%)$ patients in categories 2 and 3 respectively postoperatively with no statistically significant difference $(p>0.05)$ between pre and postoperative findings. However in group B (Outer displacement of hypertrophied inferior turbinate) moderate and mild nasal obstruction was recorded in $21(18.75 \%)$ and $23(20.53 \%)$ patients respectively preoperatively while postoperative moderate and mild nasal obstruction was observed in $13(11.60 \%)$ and $17(15.17 \%)$ patients respectively. Statistical analysis by Chi-square test showed no significant difference between the two operations $(p>0.05)$. Table 3 .

Table 3: Finding of Objective Assessment of both groups pre and postoperatively.

\begin{tabular}{|c|c|c|c|c|c|c|c|c|c|c|c|}
\hline \multirow{3}{*}{ Category } & \multirow{3}{*}{$\begin{array}{c}\text { Nasal Air } \\
\text { Passage } \\
\text { (cm) }\end{array}$} & \multicolumn{4}{|c|}{ Group A } & \multirow{3}{*}{$\begin{array}{c}\text { P- } \\
\text { Value }\end{array}$} & \multicolumn{4}{|c|}{ Group B } & \multirow{3}{*}{$\begin{array}{c}\text { P. } \\
\text { Value }\end{array}$} \\
\hline & & \multicolumn{2}{|c|}{ Preop } & \multicolumn{2}{|c|}{ Postop } & & \multicolumn{2}{|c|}{ Preop } & \multicolumn{2}{|c|}{ Postop } & \\
\hline & & Frequency & \%age & Frequency & \%age & & Frequency & \%age & Frequency & \%age & \\
\hline 1 & $<1.9$ & 5 & 4.46 & 1 & 0.9 & \multirow{4}{*}{$>0.05$} & 3 & 2.6 & 0 & 0 & \multirow{4}{*}{$>0.05$} \\
\hline 2 & 22.9 & 25 & 22.32 & 14 & 12.5 & & 21 & 18.75 & 13 & 11.60 & \\
\hline 3 & 33.9 & 19 & 16.96 & 18 & 16.07 & & 23 & 20.53 & 17 & 15.17 & \\
\hline 4 & $>4$ & 7 & 6.25 & 23 & 20.53 & & 9 & 8.03 & 26 & 23.21 & \\
\hline
\end{tabular}

The complications experienced in this study were post operative bleeding in $3(2.6 \%)$ patients, adhesion formation in $4(3.5 \%)$ patients and crusting in $2(1.78 \%)$ patients with no statistically significant difference $(p>0.05)$ between the two surgical techniques.

\section{DISCUSSION}

In this study we observed that majority of patents were in $3^{\text {rd }}$ and $4^{\text {th }}$ decade of life, presented in age range from 16 to 50 years with male to female ratio of $1.7: 1$ and mean age was $32.92 \pm$ S.D 10.29 years that is in accordance with results of Reddy where the minimum age was 14 years and maximum was 60 years. The highest incidence was found to be in the age of 20 to 29 years $(40 \%)$ followed by 30 to 39 years $(23.33 \%)$ and $59.99 \%$ were males and $40 \%$ were females with male to female ratio of $1.5: 1 .{ }^{10}$ Likely Kumar reported that the ages of patients varied from 19 years to 55 years with a mean age of $27.82 .{ }^{11}$ Our study is also supported by research of Gomaa who found that patients were in the age range of $16-43$ years (mean age $26.1 \pm 6.6$ years), males were $34(68 \%)$ and females were $16(32 \%)$ with male to female ratio of $2.1: 1 .^{12}$ The hypertrophy of inferior turbinate may be caused due to a number of reasons including excessive mucosal layer thickness, hypertrophy of lamina propria housing subepithelial inflammatory cells and venous sinusoids or increased size of turbinate bony component. Surgical treatment of hypertrophied turbinated practiced yet are controversial and so many techniques have been exercised by many otolaryngologist to reduce the size of hypertrophied turbinate for relief of nasal obstruction with a success rate ranging from 70 to $80 \% .^{12}$ But beside improvement in airway there are associated complications too in forms of synachae, crusting and bleeding, that why this study is carried out which is rather more tissue preserving technique. On subjective assessment of patients pre-operative nasal obstruction was found in all $112(100 \%)$ patients. Three months after surgery nasal obstruction remained in $3(2.6 \%)$ patients in Group A, in 4(3.5\%) patients in Group B with relief from nasal obstruction of $94.64 \%$ and $92.86 \%$ in Group A and B respectively. The improvement in nasal discharge was $81.49 \%$ and $63.16 \%$ in group $A$ and $B$ and headache was relived $83.34 \%$ and $88.38 \%$ in Group A and B respectively. Similarly Hassoun conducted a comparative study between turbinoplasty and submucosal diathermy of inferior turbinate and revealed that the most common presenting symptom was nasal blockage $(100 \%)$, followed by rhinorrhoea $(50 \%))^{13} \mathrm{He}$ noted that nasal obstruction was $24 \%$ in grade 1 , 
$48 \%$ in grade 2 and $28 \%$ in grade 3 . Moreover the nasal obstruction was significantly improved; $100 \%$ with turbinoplasty and $92 \%$ in submucous diathermy group after a month $(p=0.005) .{ }^{13}$

In current study in group A (anterior trimming of inferior turbinate) there were $25(22.32 \%)$ patients in category 2 and $19(16.96 \%)$ patients in category 3 preoperatively which were reduced to $14(12.5 \%)$ and $18(16.07 \%)$ patients in categories 2 and 3 respectively postoperatively with significant difference $(p<0.05)$ between pre and postoperative findings. However in group $B$ (outer displacement of inferior turbinate) moderate and mild nasal obstruction was recorded in $21(18.75 \%)$ and $23(20.53 \%)$ patients respectively preoperatively while postoperative moderate and mild nasal obstruction was observed in $13(11.60 \%)$ and $17(15.17 \%)$ patients respectively. Statistical analysis by Chi-square test showed no significant difference between the two operations $(p>0.05)$. These observations are keeping with results of Hamerschmidt, who studied effect of turbinoplasty and found that on $90^{\text {th }}$ day there was markable improvement in nasal obstruction as there was no crust or edema and there was no statistically significant differences between the groups $(p=0.808) \cdot{ }^{14}$ Similarly Gomaa also assessed the patients objectively for nasal patency after 3 months and noted that in turbinoplasty group mean percentage of nasal patency was increased from 6.6 preoperatively to 19.6 , which was statistically significant $(p=0.000)$, while in submucosal diathermy group mean percentage of nasal patency was increased from 6.1 preoperatively to 14.4 , which was also statistically significant $(p=0.000) .{ }^{12}$ Rai recorded $100 \%$ improvement in nasal obstruction 3 months after surgery in both conventional and endoscopic groups, with no statistical difference between endoscopic and conventional techniques $(p>0.05) .{ }^{15}$ The complications experienced in this study were post operative bleeding in $3(2.6 \%)$ patients, adhesion formation in $4(3.5 \%)$ patients and crusting in $2(1.78 \%)$ patients with no statistically significant difference $(p>0.05)$ between the two surgical techniques. However in Reddy study complications rate was as high as $75 \%$ for infection, crusting bleeding and adhesion. ${ }^{10}$ Regarding complication our study differs from Barham study, who found that post operative pain found in electrocautery, submucosal diathermy and turbinoplasty was $22 \%, 9 \%$ and $14 \%$ respectively with statistically significant difference $\left(x^{2}=4.84, p=0.089\right)$. Post operative crusting found in electrocautery, submucosal diathermy and turbinoplasty was $58 \%, 2 \%$ and $0 \%$ respectively with statistically significant difference $\left(X^{2}=92.04, p<0.001\right)$. ${ }^{16}$ There was minimal resection of inferior turbinate in our study, which may be a reason for minimal complication. Like other studies it is noted that there was no statistically significant difference between the two surgical procedures for reduction of inferior turbinate hypertrophy. The limitation of this study was follow-up for three months so more studies with long follow up may be required.

\section{CONCLUSION}

It is concluded that both trimming and outer displacement after superiomedial infracture of hypertrophied inferior turbinate are effective procedures for relief of nasal obstruction but there was no significant difference between the two techniques in term of outcome and complications. Moreover no severe postoperative complications were noted. Still to know long term results of these techniques more studies with large sample size are required.

\section{REFERENCES}

1. Moura BH, Migliavacca RO, Lima RK, Dolci JE, Becker M, Feijó C et al. Partial inferior turbinectomy in rhinoseptoplasty has no effect in quality-of-life outcomes: a randomized clinical trial. Laryngoscope 2018; 128(1):57-63.

2. Lee DC, Jin SG, Kim BY, Yoo S, Han S, Lee YJ et al Does the effect of inferior turbinate out fracture persist? Plast Reconstr Surg. 2017; 139(2):386-391.

3. Smith $\mathrm{DH}$, Brook $\mathrm{CD}$, Virani S. The inferior turbinate: An autonomic organ. Am J Otolaryngol. 2018; 39:771-75. https:// doi:10.1016/j.amjoto.2018.08 009.

4. Choi JH, Lee JK, Cho SH. Inferior turbinate surgery in sleep-disordered breathing patients with nasal obstruction: Principles and various techniques. Sleep Medicine Research, 2018; 9(1), 20-25. https://doi.org/10.17241/smr.2018.00143.

5. Bakshi SS, Manoharan KS, Gopalakrishnan S Comparison of the long term efficacy of radiofrequency ablation and surgical turbinoplasty in inferior turbinate hypertrophy: a randomized clinical study. Acta Oto-Laryngologica 2017; 137(8):856-61.

6. Khan N, Arshad M, Ahmad T, Ashfaq M.Total inferior turbinectomy for hypertrophied inferior turbinates: postoperative results in 135 patients. PAFMJ 2005 ; 55 (3): $187-192$. https://www.pafmj.org/index.php/PAFMJ/article/vie $w / 1261$.

7. Imad, Javed, Sanaullah. Comparison of Submucosal Diathermy with Partial Inferior Turbinectomy: A Fifty Case Study. J Postgrad Med Inst. 2012; 26(1): 91-5 
8. Ahmad N, Din IU, Gul I, Rukh G. Why nasal septal surgery alone is not sufficient to relieve nasal obstruction in case of deviated nasal septum? J Med Sci 2017; 25: (1):115-18.

9. Wang X, Ji X. Sample Size Estimation in Clinical Research: From Randomized Controlled Trials to Observational Studies. Chest. 2020; 158(1):12-20. Doi: 10.1016/j.chest.2020.03.010. PMID: 32658647.

10. Reddy R. Inferior turbinectomy - outcome of various surgical modalities: a prospective study. Int J Otorhinolaryngol Head Neck Surg 2017; 3:551-4.

11. Kumar SKN, Aradhya AS. Total inferior turbinectomy versus inferior turbinoplasty- a comparative study. J. Evolution Med. Dent. Sci. 2018; 7(35):3830-3834, DOI: $10.14260 /$ jemds/2018/859.

12. Gomaa MA, Abdel Nabi OG, Abdel Kerim ARA, Aly A. Comparative Study between Partial Surgical Inferior Turbinectomy and Sub-mucosal Diathermy of Inferior Turbinate for Treatment of Inferior Turbinate Hypertrophy. Otolaryngology 2015 5: 217. Doi:10.4172/2161-119X.1000217.

13. Hassoun YL. Comparison and evaluation effect between microdebrider assisted turbinopalsty and submucosal diathermy of the inferior tubinates techniques. American Journal of Research Communication, 2015; 3(7): 47-56.

14. Hamerschmidt R, Hamerschmidt R, Moreira ATR, Tenório SB, Timi JRR. Comparison of turbinoplasty surgery efficacy in patients with and without allergic rhinitis. Braz J Otorhinolaryngol. 2016; 82:131-39.

15. Rai S, Sharma V, Koirala K, Sharma AC. Endoscopic versus conventional method for partial inferior turbinectomy in chronic hypertrophic rhinitis. Nepal Journal of Medical Sciences 2013; 2(2):102-7.

16. Barham HP, Thornton MA, Knisley A, Marcells G N , HarveyRJ, Sacks R. Long-term outcomes in medial flap inferior turbinoplasty are superior to submucosal electrocautery and submucosal powered turbinate reduction. Int Forum Allergy Rhinol. 2016; 6:143-147.
DATA SHARING STATEMENT: The data that support the findings of this study are available on request from the corresponding author. The data are not publicly available due to privacy or ethical restrictions.

CONFLICT OF INTEREST: Authors declared no conflict of interest.

GRANTED SUPPORT AND FINANCIAL DISCLOSURE: Nil

\section{AUTHOR'S CONTRIBUTION}

Following authors have made substantial contributions to the manuscript as under

Rehman HU: Concept and design of study, Wahid F: Collection of data, statistical analysis Writing of manuscript, critical review of manuscript

Zada B: Analysis and interpretation of data, statistical analysis

Javaid M, Haq N: Data collection, bibliography

Authors agree to be accountable for all aspects of the work in ensuring that questions related to the accuracy or integrity of any part of the work are appropriately investigated and resolved. 